\title{
Changing Pattern of Opioid Users Attending an Opioid Agonist Treatment Clinic in North India
}

\author{
Fazle R. Bhat ${ }^{1}$ Yasir H. Rather ${ }^{1} \quad$ Ubaid Rasool $^{1}$ \\ ${ }^{1}$ Department of Psychiatry, Institute of Mental Health and \\ Neuroscience, Government Medical College, Srinagar, Union \\ Territory of Jammu \& Kashmir, Jammu \& Kashmir, India \\ J Neurosci Rural Pract 2022;13:176-180.
}

\begin{abstract}
Address for correspondence Fazle R. Bhat, DM, Department of Psychiatry, Institute of Mental Health and Neuroscience, Kathi Darwaza Srinagar 190003, Union Territory of Jammu and Kashmir, India (e-mail: fazleroub@gmail.com).
\end{abstract}

\begin{abstract}
Objectives Illicit opioid use is a major concern across the globe due to its adverse health consequences. Pharmacological intervention is regarded as the cornerstone of management of opioid dependence and the Opioid Agonist Treatment (OAT) is the most effective intervention for this chronic relapsing disorder. Since the pattern of use of illicit substances, like opioids, changes with the course of time, we studied the profile of patients registered in an OAT clinic of a tertiary care center in North India over last 8 years.

Methods Retrospective chart review of patients registered in the OAT clinic was done. Comparisons were made among two periods (2012-2015 and 2016-2019).

Results Total number of opioid dependent patients registered in OAT clinic has increased from 139 in 2012 to 2015 to 309 in 2016 to 2019. Mean age at the first use of opioids has reduced significantly from $20.2( \pm 2.7)$ years in 2012 to 2015 to $18.3( \pm 3.2)$ years in 2016 to $2019(p=0.02)$. Parenteral route continues to remain as the dominant mode of use of opioids, though it has increased from 80.6 to $99 \%$ of users. There has been increased use of heroin over these years (12.2\% in 2012-2015 to $72.5 \%$ in 2016 -

\section{Keywords}

- dependence

- opioids

- opioid substitution

- trends

19) with concomitant decrease of pentazocine use (69.1-17.5\%), respectively.

Conclusion The changing demographic and opioid use pattern in the last couple of years among patients attending OAT clinic should alert the policy makers, so that an integrated approach is put into action for effective prevention and management of opioid use disorders.
\end{abstract}

\section{Introduction}

Worldwide, over 26 million individuals are suffering from opioid use disorder, with the highest prevalence in North America. ${ }^{1}$ As far as mortality and disability-adjusted lifeyears (DALYs) are concerned, opioids score higher than other illicit substances. ${ }^{2,3}$

published online February 9, 2022
DOI https://doi.org/ 10.1055/s-0041-1736509. ISSN 0976-3147.
The Opioid Agonist Treatment (OAT) or Opioid Substitution Treatment (OST) for opioid-dependent patients is an evidence-based and effective treatment for management of opioid dependence syndrome. ${ }^{4}$ It involves supervised administration of safer and longer acting opioids, such as buprenorphine or methadone, on a long-term basis, relieving opioid-related withdrawal/craving with eventual reduction

(c) 2022. Association for Helping Neurosurgical Sick People. All rights reserved.

This is an open access article published by Thieme under the terms of the Creative Commons Attribution-NonDerivative-NonCommercial-License, permitting copying and reproduction so long as the original work is given appropriate credit. Contents may not be used for commercial purposes, or adapted, remixed, transformed or built upon. (https://creativecommons.org/ licenses/by-nc-nd/4.0/)

Thieme Medical and Scientific Publishers Pvt. Ltd., A-12, 2nd Floor, Sector 2, Noida-201301 UP, India 
in the use of opioids. OAT allows patients to focus more time and energy on seeking employment and other socially productive activities. OAT is the most effective treatment modality for treatment retention and reduction in illicit opioid use. ${ }^{5}$ In India, buprenorphine is the most common available opioid in OAT centers.

Pattern of illicit drug use in any region varies with the local availability of substances, cultural factors, and substance regulatory laws. ${ }^{6}$ Kashmir has witnessed an increased seizures of opioids from last couple of years owing to both cross-border and interstate smuggling. ${ }^{7,8}$ The situation is further complicated with the increased rates of opioid users seeking treatment from service providers located in Kashmir. ${ }^{9,10}$ The recent nationwide study documented that approximately $4.91 \%$ population of Jammu \& Kashmir uses opioids currently which is higher than the national percentage of $2.06 \%{ }^{11}$ Despite these staggering figures, not many studies have been conducted into the opioid use pattern among treatment-seeking population.

In view of the above-mentioned facts, the authors decided to embark on this study, so that we can get to know about the change in opioid use pattern as OAT could act as an indirect marker of opioid use pattern.

\section{Methodology}

This was a retrospective study assessing individuals registered in OAT Clinic at a tertiary care addiction services unit of North India. The institute has an inpatient ( 30 beds), as well as outpatient, facility and caters to whole of Kashmir division having an average flow of 40 patients daily. At our center, individuals with opioid dependence syndrome as per the International Classification of Diseases, 10th version (ICD10) criteria, a minimum duration of 2 years of opioid use, using a high-potency opioids like heroin preferably via injection route and having at least one failed attempt of nonopioid medication or opioid-assisted withdrawal management are offered sublingual tablets of buprenorphine as part of pharmacoprophylaxis. ${ }^{12,13}$

The OAT treating team is a multidisciplinary and includes one qualified psychiatrist, a trainee psychiatrist, one medical social worker, a counsellor, and a pharmacist who work under guidance of a consultant psychiatrist. After an induction phase, patients receive tablet buprenorphine on a daily basis and are tested for opioids using chemiluminescence immune assay at least once a month.

Patients registered in the OAT clinic were divided into two groups, 2012 to 2015 and 2016 to 2019. Case files of patients registered in OAT clinic between January 1, 2012, to December 31, 2019, were retrieved by two of the investigators (F.R. B. and U.R.).The information extracted included sociodemographic (like age, gender, marital status, and residence), clinical and treatment related variables such as type of the opioid used, mode of opioid intake, and high-risk behavior.

\section{Statistical Analysis}

Statistical analysis was done using the SPSS version 21.0 (IBM Corp. Released 2012. IBM SPSS Statistics for Windows, ver- sion 21.0. Armonk, New York, United States: IBM Corp.). Descriptive statistics, Chi-square test, Fisher's exact test, and $t$-test were used to analyze the data wherever applicable.

\section{Results}

\section{Sociodemographic Profile}

As shown in - Table 1, there has been an increase in patient enrollment; it was 139 for the first period (2012-2015) and increased to 309 in the second period. Mean age of the patients has reduced from $30.3( \pm 8.6)$ to $28.1( \pm 7.7)$ years $(p<0.01)$. There has been a shift from an urban to rural population predominance between these two periods (94.2$52.1 \%, p<0.01)$.

\section{Trends of Change in Clinical Profile}

Mean age at the initiation of illicit opioids has reduced from $20.2( \pm 2.7)$ to $18.3( \pm 3.2)$ years $(p<0.01)$. For both the time periods, the predominant mode of opioid use was injection route, though there was an increase from 80.6 to $99.0 \%$ $(p<0.01)$. While there was a decrease in pentazocine use (from 69.1 to $17.5 \%$ ), there was a concomitant increase in heroin use (from 12.2 to $72.5 \%, p<0.01$; - Table 2 ).

\section{Discussion}

To the best of our knowledge, this is the first study from India that analyzed trend of individuals with opioid dependence who were registered in OAT. Our study revealed (1) an increase in the number of patients being enrolled in OAT, (2) a reduction in the age at the first use of opioids, and (3) heroin being the commonest opioid for which patients were being started on OAT.

An increase in the enrolment in OAT clinic suggests either an increased awareness regarding treatment seeking or an increase in the use of more potent illicit opioids, like heroin, for which there is enough evidence of effectiveness of OST. ${ }^{4}$ Recently, an increase in the use of injection heroin has been reported from Kashmir which was uncommon years before. ${ }^{9}$ This also coincides with the fact that the injection drug use has been on the rise in whole country and the union territory of Jammu \& Kashmir remains no exception. ${ }^{11}$ The geographical location of Kashmir makes it an ideal for the transport of opioids from neighboring states like Punjab, as well as via border from Pakistan.

Reduction in the age at initiation of opioids raises the concern that the adolescent and young adults are landing in the opioid use at an early age which needs attention from policy makers. Similar concern has been raised from studies conducted in different parts of India. ${ }^{14-16}$ Medhi et al also reported that individuals registered in OAT were predominantly males in the age group of 15 to 35 years. ${ }^{17}$ Current study had similar results as majority of the patients were in the same age group, though in our study, the predominant age subgroup had shifted from 26 to 35 years to below 25 years during these time periods. A low percentage of female users is common in studies from India in contrast to the studies from the West. ${ }^{9-11,14}$ An overall lower prevalence 
Table 1 Sociodemographic profile of individuals on the Opioid Agonist Therapy

\begin{tabular}{|c|c|c|c|}
\hline \multirow[t]{2}{*}{ Variable } & $2012-2015(n=139)$ & $2016-2019(n=309)$ & \multirow{2}{*}{$\begin{array}{l}\text { Chi-square or Fisher's } \\
\text { exact test/unpaired } t \text {-test }(p)\end{array}$} \\
\hline & Frequency (\%)/mean (SD) & Frequency (\%)/mean (SD) & \\
\hline Mean age (y) & $30.3(8.6)$ & $28.1(7.7)$ & $340.88(<0.001)$ \\
\hline \multicolumn{4}{|l|}{ Age (y) } \\
\hline Up to 25 & $39(28.1)$ & $108(35.0)$ & $22.70(<0.01)$ \\
\hline $26-35$ & $82(59.0)$ & $164(53.1)$ & $24.20(<0.01)$ \\
\hline $36-45$ & $12(8.6)$ & $28(9.1)$ & $0.02(1.0)$ \\
\hline Above 45 & $6(4.3)$ & $9(2.9)$ & $0.58(0.57)$ \\
\hline \multicolumn{4}{|l|}{ Gender } \\
\hline Male & 137 (98.6) & $303(98.1)$ & $0.14(1.00)$ \\
\hline Female & $2(1.4)$ & $6(1.9)$ & $0.14(0.71)$ \\
\hline \multicolumn{4}{|l|}{ Marital status } \\
\hline Married & $83(59.7)$ & $80(25.9)$ & $46.56(<0.01)$ \\
\hline Unmarried & $51(36.7)$ & $228(73.8)$ & $55.52(<0.01)$ \\
\hline Separated/widowed & $5(3.6)$ & $1(0.3)$ & $7.14(<0.01)$ \\
\hline \multicolumn{4}{|l|}{ Residence } \\
\hline Urban & $131(94.2)$ & $148(47.9)$ & $87.66(<0.01)$ \\
\hline Rural & $8(5.8)$ & $161(52.1)$ & $87.66(<0.01)$ \\
\hline \multicolumn{4}{|l|}{ Occupation } \\
\hline Student & $35(25.2)$ & $60(19.4)$ & $1.86(0.17)$ \\
\hline Unemployed & $23(16.5)$ & $65(21.0)$ & $1.25(0.30)$ \\
\hline Self-employed & $77(55.4)$ & $166(53.7)$ & $0.11(0.76)$ \\
\hline Govt. employee & $4(2.9)$ & $18(5.8)$ & $1.96(0.24)$ \\
\hline
\end{tabular}

Abbreviation: SD, standard deviation.

of opioid use and higher levels of stigma attributed to the female substance use in traditional societies, like ours, could be other reasons for lower representation of females in substance-related programs. ${ }^{18}$ There was a significant change in the profile of individuals started on OAT as far as locality is concerned. Between 2016 and 2019, more than half of the individuals started on OAT were of rural background which was dominated by the individuals of urban background in 2012 to 2015. Since the center is located in an urban area, this could explain the predominance of individuals with urban background in the earlier period. With due course of time, greater awareness regarding treatment options could explain the above observation. Another important finding is that greater number of unemployed and self-employed persons are using opioids; though there was no significant change as far as occupation was concerned. This could be explained by the fact that Kashmir has been facing incessant curfews from last few years in view of three-decade-long armed conflict. Boredom and a greater prevalence of psychiatric disorders in conflictridden areas usually lead to increased substance use, and it could also explain this phenomenon in Kashmir in these two groups. ${ }^{19}$

An area of concern that necessitates immediate intervention of policy makers is that the relatively safer routes for use of opioids, like chasing and oral, have been replaced with intravenous route. A striking finding has been that the heroin has almost replaced all other opioids like pentazocine and natural opioids. Basu et al also reported that there was change in substance use pattern, younger people seeking treatment and increasing use of illicit opioids like heroin. ${ }^{14} \mathrm{~A}$ multicentric study from India also reported that majority of the individuals on OAT were heroin users, as there is robust evidence for the efficacy of OST among heroin users. ${ }^{20}$ Regional availability, costs, and substance users' perception about the effects and safety of a particular drug are believed to determine the choice of a specific drug. ${ }^{21}$ This could also mean that heroin is easily available as compared with pharmaceutical opioid, like pentazocine, which has to be procured from pharmacies. Heroin users have been found to have a higher degree of drug use, poor sociooccupational functioning, and better treatment seeking as compared with pharmaceutical opioid users; this could also be another factor for increased number of individuals' seeking treatment at the center. ${ }^{22}$

Between 2012 to 2015 and 2016 to 2019, there has been a significant increase in the rates of sharing of needles/syringes which increases the risk of parenterally transmitted infections like HCV and HIV. Sharing of needles and syringes by injecting drug users (IDUs) is not an uncommon practice 
Table 2 Comparison of clinical profile of patients between 2012-2015 and 2016-2109

\begin{tabular}{|c|c|c|c|}
\hline \multirow[t]{2}{*}{ Variable } & $2012-2015(n=139)$ & $2016-2019(n=309)$ & \multirow{2}{*}{$\begin{array}{l}\text { Chi-square or Fisher's } \\
\text { exact test/unpaired } t \text {-test }(p)\end{array}$} \\
\hline & Frequency (\%)/mean (SD) & Frequency (\%)/mean (SD) & \\
\hline $\begin{array}{l}\text { Mean age at first use } \\
\text { of opioids (years) }\end{array}$ & $20.2(2.7)$ & $18.3(3.2)$ & $2.33(0.02)$ \\
\hline \multicolumn{4}{|l|}{ Mode of opioid use } \\
\hline Oral & $16(11.5)$ & $2(0.6)$ & $29.34(<0.01)$ \\
\hline Chasing & $11(7.9)$ & $1(0.3)$ & $21.35(<0.01)$ \\
\hline Parenteral & $112(80.6)$ & $306(99.0)$ & $52.25(<0.01)$ \\
\hline \multicolumn{4}{|l|}{ Type of opioid used } \\
\hline Heroin & $17(12.2)$ & $224(72.5)$ & $140.07(<0.01)$ \\
\hline Pentazocine & $96(69.1)$ & $54(17.5)$ & $114.57(<0.01)$ \\
\hline Tramadol/tapentadol & $12(8.6)$ & $29(9.4)$ & $0.06(0.86)$ \\
\hline Natural opioids & $9(6.5)$ & $1(0.3)$ & $16.62(<0.01)$ \\
\hline Others & $17(12.2)$ & $29(9.4)$ & $0.84(0.40)$ \\
\hline \multicolumn{4}{|l|}{ High-risk behavior } \\
\hline Reuse of needles & $36(25.9)$ & $61(19.7)$ & $2.14(0.17)$ \\
\hline Sharing of needles/syringes & $108(77.7)$ & $269(87.1)$ & $6.09(0.02)$ \\
\hline History of contact with CSW & $36(25.9)$ & $109(35.3)$ & $3.85(0.05)$ \\
\hline Mean daily dose of buprenorphine & $3.69(1.7)$ & $4.44(1.7)$ & $4(0.06)$ \\
\hline \multicolumn{4}{|l|}{ Comorbid substance use } \\
\hline Alcohol & $95(68.3)$ & $30(9.7)$ & $171.40(<0.01)$ \\
\hline Cannabis & $49(53.3)$ & $54(43.9)$ & $163.09(<0.01)$ \\
\hline Tobacco & $56(60.9)$ & $67(54.5)$ & $0.01(1.00)$ \\
\hline
\end{tabular}

Abbreviation: CSW, commercial sex worker; SD, standard deviation.

in India. One study from Northeastern states of India reported that sharing of needles and syringes ranged from 57.6 to $95.6 \%{ }^{20}$ While harm reduction approaches like needle-syringe exchange programs and OST have been expanded in these states, there has not been any appreciable extension in Jammu \& Kashmir. As per the recent nationwide survey, Jammu \& Kashmir had more than 25,000 injection drug users and, hence, there is an urgent need to upgrade harm reduction services like OST and needle-syringe exchange program. ${ }^{11}$ Discriminatory and negative attitude of doctors and community, as well as sociopolitical environment, in any region are important barriers in the expansion of harm reduction services. ${ }^{23}$

In the current study, the average daily maintenance dose of buprenorphine has increased but is still less as has been deemed good for Indian population (6-12 mg). Dosage lesser than $6 \mathrm{mg}$ has been shown to have an increased risk for relapse as compared with a higher dosage. ${ }^{24}$ Another study from India also reported a lower dosage of OST similar to the current study. ${ }^{25}$

Another interesting observation was a decreasing trend of comorbid substance use disorders like cannabis and alcohol. Could this be alluded to the fact that there is difficulty in procuring these substance (as alcohol is considered a taboo in a conservative Muslim society like Kashmir) or more adolescents experimenting with opioids directly, only future studies could make us wiser?

To the best of our knowledge, this was the first study from India which assessed the changing pattern of opioid use among patients on OAT. The study analyzed data since the initiation of OAT in Kashmir valley along with retrieval of whole data. Findings of the current study are also important, since it is imperative to have information regarding the changing trends of substance use in general and type or mode of opioid use in particular. ${ }^{14}$

\section{Limitations}

Our study has few limitations. The findings may not be generalized to community as our study was conducted among the treatment-seeking population. OAT clinic may not be an accurate predictor of opioid users as recruitment is also influenced by clinician. Also, OST is usually chosen for difficult-to-treat patients, and there will be less representation of low-potency opioids (like natural opioids and pharmaceutical opioids such as codeine, tramadol, and others). There may be potential inaccuracies in documenting the records since this was a retrospective study. Last but not the least, we did not assess the comorbid psychiatric illness and their relationship with the changing pattern of opioid use. 


\section{Conclusion}

To conclude, current study highlights a major shift in the pattern and profile of opioid users started on OAT. Heroin is now the most common opioid among individuals on OAT while as injection route remains the commonest one. Since only approximately $20 \%$ of IDUs receive OAT every year, policy makers should focus on expansion of OAT. ${ }^{26}$ Future studies could look into the past treatment options, drop-out rates, and change in high-risk behavior after being started on OAT. More research, especially of prospective nature, is required to look into the factors associated with the high-risk behavior among IDUs.

\section{Ethical Approval}

The study was approved by Ethical Committee of Government Medical College Srinagar.

\section{Authors' Contributions}

F.R.B.: final draft of the article, data analysis and interpretation, collection, and assembly of data; Y.H.R.: concept and design, critical revision of the article for intellectual content, and final draft.; and U.R.: collection and assembly of data and initial draft of the article.

\section{Conflict of Interest}

None declared.

\section{References}

1 Degenhardt L, Charlson F, Ferrari A, et al; GBD 2016 Alcohol and Drug Use Collaborators. The global burden of disease attributable to alcohol and drug use in 195 countries and territories, 19902016: a systematic analysis for the Global Burden of Disease Study 2016. Lancet Psychiatry 2018;5(12):987-1012

2 Degenhardt L, Whiteford HA, Ferrari AJ, et al. Global burden of disease attributable to illicit drug use and dependence: findings from the Global Burden of Disease Study 2010. Lancet 2013;382 (9904):1564-1574

3 Hser YI, Hoffman V, Grella CE, Anglin MD. A 33-year follow-up of narcotics addicts. Arch Gen Psychiatry 2001;58(05):503-508

4 Mattick RP, Breen C, Kimber J, Davoli M. Buprenorphine maintenance versus placebo or methadone maintenance for opioid dependence. Cochrane Database Syst Rev 2014;(02):CD002207

5 Ghosh A, Basu D, Avasthi A. Buprenorphine-based opioid substitution therapy in India: A few observations, thoughts, and opinions. Indian J Psychiatry 2018;60(03):361-366

6 Sharma HK. Sociocultural perspective of substance use in India. Subst Use Misuse 1996;31(11-12):1689-1714

7 ENS Economic Bureau. Over $200 \mathrm{~kg}$ heroin seized in J\&K in AugustJanuary. Accessed January 28, 2021 at: https://indianexpress. com/article/business/over-200-kg-heroin-seized-in-jk-in-augustjanuary-5612911/

8 Majid Z. About $1 \mathrm{~kg}$ heroin seized from Srinagar hotel; 2 held. Accessed March 18, 2021 at: https://www.deccanherald.com/ national/north-and-central/about-1-kg-heroin-seized-from-srinagar-hotel-2-held-963146.html

9 Rather YH, Bhat FR, Malla AA, Zahoor M, Ali Massodi PA, Yousuf S. Pattern and prevalence of substance use and dependence in two districts of Union Territory of Jammu \& Kashmir: Special focus on opioids. J Family Med Prim Care 2021;10(01):414-420

10 Rather YH, Bashir W, Sheikh AA, Amin M, Zahgeer YA. Sociodemographic and clinical profile of substance abusers attending a regional drug de-addiction centre in chronic conflict area: Kashmir, India. Malays J Med Sci 2013;20(03):31-38

11 Ambekar A, Chadda RK, Khandelwal SK, Rao R, Mishra AK, Agrawal A. National Drug Dependence Treatment Centre (NDDTC), All India Institute of Medical Sciences (AIIMS), New Delhi. Magnitude of substance use in India: 2019. Executive summary. Accessed September 13, 2021 at: http://www.ndusindia.in/ downloads/Magnitude_India_EXEUCTIVE_SUMMARY.pdf

12 World Health Organization. International Classification of Diseases 10th revision. Accessed September 13, 2021 at: https:// www.cdc.gov/nchs/icd/icd10.htm

13 World Health Organization. The ICD-9 classification of mental and behavioural disorders: Clinical descriptions and diagnostic guidelines. Geneva: World Health Organization; 1978

14 Basu D, Aggarwal M, Das PP, Mattoo SK, Kulhara P, Varma VK. Changing pattern of substance abuse in patients attending a deaddiction centre in north India (1978-2008). Indian J Med Res 2012;135(06):830-836

15 Venkatesan J, Suresh SSD. Substance dependence: Decades apart in a teaching hospital. Indian J Psychiatry 2008;50(02):100-105

16 WHO Biennium Project (2006-2007). Report: drug abuse monitoring system (SE/06/226877 \& SE/07/117746). Accessed December 4, 2020 at: https://www.scribd.com/document/37754060/ Mental-Health-Substance-Abuse-Drug-Abuse-Monitoring-System

17 Medhi GK, Mahanta J, Adhikary R, et al. Spatial distribution and characteristics of injecting drug users (IDU) in five Northeastern states of India. BMC Public Health 2011;11:64

18 Lal R, Deb KS, Kedia S. Substance use in women: current status and future directions. Indian J Psychiatry 2015;57(Suppl 2): S275-S285

19 Lai L. Treating substance abuse as a consequence of conflict and displacement: a call for a more inclusive global mental health. Med Confl Surviv 2014;30(03):182-189

20 Armstrong G, Kermode M, Sharma C, Langkham B, Crofts N. Opioid substitution therapy in Manipur and Nagaland, northeast India: operational research in action. Harm Reduct J 2010; 7:29

21 McCabe SE, Cranford JA, Boyd CJ, Teter CJ. Motives, diversion and routes of administration associated with nonmedical use of prescription opioids. Addict Behav 2007;32(03):562-575

22 Assari S, Ahmadi K, Rezazade M. Socio-economic status determines risk of receptive syringe sharing behaviors among Iranian drug injectors; a national study. Front Psychiatry 2015;5:194

23 Hangzo C, Chatterjee A, Sarkar S, Zomi GT, Deb BC, Abdul-Quader AS. Reaching out beyond the hills: HIV prevention among injecting drug users in Manipur, India. Addiction 1997;92(07): 813-820

24 Reimer J, Vogelmann T, Trümper D, Scherbaum N. Impact of buprenorphine dosage on the occurrence of relapses in patients with opioid dependence. Eur Addict Res 2020;26(02):77-84

25 Mohapatra S, Nayak MR, Dash M. A clinical study of opioid substitution therapy in a tertiary care center of Eastern India. Indian J Psychol Med 2017;39(06):756-759

26 Larney S, Peacock A, Leung J, et al. Global, regional, and countrylevel coverage of interventions to prevent and manage HIV and hepatitis $C$ among people who inject drugs: a systematic review. Lancet Glob Health 2017;5(12):e1208-e1220 